\title{
Alphanumerical order and category effects in visual search
}

\author{
LESTER E. KRUEGER and LAWRENCE J. HETTINGER \\ Ohio State University, Columbus, Ohio
}

\begin{abstract}
Is regular alphanumerical order so overlearned that it can aid visual search? Regular (vs. random) order did not help letter or digit search, whereas reverse order (e.g., 987654, FEDCBA) hurt, perhaps because it evoked a tendency to scan in an unnatural, right-to-left fashion. The same order effects were found on between-category trials as on within-category trials. There was a between-category speed advantage on letters versus digits, as well as on early (A to $J$ ) versus late ( $Q$ to $Z$ ) letters, but not on odd versus even digits. The between-category speed advantage was only slightly larger when the target set size was 2 rather than 1 , which indicates that its main locus was at the initial encoding or perceptual analysis.
\end{abstract}

Physical differences can greatly speed letter or digit search (Neisser, 1967). Higher level properties of the background also may help. Thus, a target letter (digit) is detected more readily in a digit (letter) background (Ingling, 1972; Jonides \& Gleitman, 1972), and in a word than in a nonword (Krueger, 1975). The present study attempts to extend the letter versus digit category effect to include the odd-digit versus even-digit contrast and the early-letter (A to $J$ ) versus late-letter ( $Q$ to $Z$ ) contrast (Experiment 2), and to extend the word-superiority effect to include regular alphabetical and numerical order (Experiments 1 and 2). No norms exist on the frequency of occurrence of regular alphabetical and numerical order, but it surely must equal or exceed that for most words.

\section{EXPERIMENT 1}

The four different background orders (regular, alternating, reverse, random) used for letters and numerals are shown in Table 1. The random order was fixed and thus had the same frequency of occurrence as each of the other orders. In the alternating order, every other member in the regular order was selected, which thus separated the odd digits from the even ones, 0246813579 . The letter sequences were slightly modified (e.g., U preceded $\mathbf{R}$ in the regular order), in order to equate them on bigram frequency (Mayzner \& Tresselt, 1965).

Familiar ascending order is perfectly preserved in regular order, partially preserved in alternating and random order, and totally missing in reverse order, and performance was expected to vary in that order. Regular order

This study was supported in part by National Institute of Mental Health Grant MH32295. Helpful comments were provided on an earlier draft by Jonathan Baron, John Duncan, John M. Flach, Robert Proctor, and Ronald G. Shapiro. Requests for reprints should be sent to Lester E. Krueger, Human Performance Center, Ohio State University, 404-B West 17th Avenue, Columbus, OH 43210-1285. might not only facilitate the scan per se, but also allow the subject to jump immediately to the target character's known position. Such bypassing was prevented on some trials by having the target differ in class (letter, digit) from the background.

Target set size was varied in order to separate encoding (intercept) effects of alphanumerical order and category from memory-comparison (slope) effects (Sternberg, 1969). If the category effect depends on physical rather than conceptual differences (Krueger, 1984), then it ought to aid only the initial encoding or perceptual analysis.

Some subjects searched for target presence (zero or one row with a target) and others for target absence (zero or one row without a target). The main effects of search task, target presence, display size, and target set size largely replicated the results of Krueger and Shapiro (1980) and will not be reported here.

Table 1

Experiments 1 and 2: Sequences Used by Background Order and Class

\begin{tabular}{|c|c|c|}
\hline \multirow{2}{*}{$\begin{array}{l}\text { Background Order } \\
\text { Experiment } 1\end{array}$} & \multicolumn{2}{|c|}{ Background Class } \\
\hline & Numeral & Letter \\
\hline $\begin{array}{l}\text { Regular } \\
\text { Alternating } \\
\text { Reverse } \\
\text { Random }\end{array}$ & $\begin{array}{l}0123456789 \\
0246813579 \\
9876543210 \\
2073158469\end{array}$ & $\begin{array}{l}\text { JKLMNPURST } \\
\text { JLNUSTKMPR } \\
\text { TSRUPNMLKJ } \\
\text { UTLKRSNJMP }\end{array}$ \\
\hline Experiment 2 & Odd & Even \\
\hline $\begin{array}{l}\text { Regular } \\
\text { Reverse } \\
\text { Random }\end{array}$ & $\begin{array}{l}13579 \\
97531 \\
91537\end{array}$ & $\begin{array}{c}02468 \\
86420 \\
02648 \text { or } 80426\end{array}$ \\
\hline Random & Early & Late \\
\hline $\begin{array}{l}\text { Regular } \\
\text { Reverse } \\
\text { Random }\end{array}$ & $\begin{array}{l}\text { ABCDEFGHIJ } \\
\text { JIHGFEDCBA } \\
\text { BHGCJAFDEI }\end{array}$ & $\begin{array}{l}\text { QRSTUVWXYZ } \\
\text { ZYXWVUTSRQ } \\
\text { YTWSQURXZV }\end{array}$ \\
\hline
\end{tabular}




\section{Method}

Subjects. Fourteen undergraduates searched for target presence, and another 14 for target absence. All had at least 20/30 vision (corrected).

Apparatus. Software-generated characters were presented at a 60 $\mathrm{Hz}$ refresh rate and at $32-\mathrm{cd} / \mathrm{m}^{2}$ intensity by an Imlac PDS-4 graphics computer, which measured reaction time (RT) to an accuracy of $1 \mathrm{msec}$. Each subject sat alone in a dark room, with the head held in a chinrest located $70 \mathrm{~cm}$ from the display screen.

Stimulus materials. Each character was $.29 \mathrm{~cm}$ wide and $.43 \mathrm{~cm}$ high, with $.43 \mathrm{~cm}$ between characters and $.29 \mathrm{~cm}$ between rows. Each row of six characters thus was $3.89 \mathrm{~cm}\left(3.18^{\circ}\right)$ wide. Ten digits (0 to 9) and 10 uppercase letters [ $\mathrm{J}$ to $\mathrm{U}$; the letters $\mathrm{O}$ and $\mathrm{Q}$ were excluded to avoid confusion with the numeral 0 (zero)] were used. Two characters in a sequence were removed on each block to serve as potential targets. On a between-category block, a target appeared in the usual position of its randomly paired background character. Only one target character could appear in a given row, and it was equally likely to appear in each row position. The starting position for a row varied randomly. If a row started late, for example, at 9 , the sequence cycled back to its beginning, for example, 901234 . On three-row displays, no two rows matched or had targets in the same position.

In each block, after a practice display, there were four one-row displays and six three-row displays, on half of which a critical row (i.e., target present in search for presence; target absent in search for absence) was present (once each at each row position on three-row displays). After a practice block, there were 32 regular blocks, which represented all combinations of memory set size, background order, background class (letter, digit), and target class (letter, digit). Four different random orderings of trials and target characters, and two of blocks, were used.

Procedure. The target set was shown for $3 \mathrm{sec}$ before each block of trials. On each trial, noise characters (uppercase $\mathrm{X}$ superimposed on uppercase O) filled all possible character positions for $750 \mathrm{msec}$, and then the display was shown until the subject responded. Feedback on the accuracy of the response appeared for $1.8 \mathrm{sec}$.

The subjects were asked to search as rapidly as possible, but not at the expense of accuracy, and to respond "yes" (half with a left-hand buttonpress, and the other half with a right-hand buttonpress) as soon as a critical row was detected or "no" if none was present. A trial was discarded if the RT was below $200 \mathrm{msec}$ or over $9 \mathrm{sec}$, and RT was computed for correct trials only. Analyses of variance were conducted on the data.

\section{Results}

Numeral background. As shown in Table 2, background order affected RT $(p<.001)$ and errors $(p<.025)$. In separate pairwise comparisons, the reverse order was slower and less accurate than each of the other three orders ( $p<.05$ or better in all cases). Mean RT for the regular order exceeded that for random order $(p<.05)$. Background order interacted with memory set size on RT ( $p<.025)$; regular order was relatively slow with one target and relatively fast with two. The increased number of errors on the reverse order was more evident with one target $(p<.025)$.

Letter background. As shown in Table 2, background order affected RT $(\mathrm{p}<.001)$ but not errors. In separate pairwise comparisons, alternating order was faster than each of the other three orders $(\mathrm{p}<.01$ or better in all cases). Background order interacted with memory set size on RT ( $p<.01)$; the alternating order had a larger speed advantage with two targets, and the regular order was relatively slow with one target and relatively fast with two.

Numeral vs. letter background. In a combined analysis, RT was lower for numeral (vs. letter) backgrounds $(p<.001)$ and for numeral (vs. letter) targets $(p<.01)$. Previous studies also found faster search through numeral displays (Lefton \& Fisher, 1976; McCarthy, 1976, 1979; but see Krueger, 1984). The RT advantage for numeral backgrounds was larger with two targets $(87 \mathrm{msec})$ than with one $(16 \mathrm{msec})(\mathrm{p}<.05)$, especially on search for

Table 2

Experiment 1: Mean Response Time (RT; in Milliseconds) and Percent Error Rate (PE) by Search Task, Target Set Size, Target Class, Background Class, and Background Order

\begin{tabular}{|c|c|c|c|c|c|c|c|c|}
\hline \multirow{3}{*}{$\begin{array}{c}\text { Background } \\
\text { Order }\end{array}$} & \multicolumn{4}{|c|}{ Search for Presence } & \multicolumn{4}{|c|}{ Search for Absence } \\
\hline & \multicolumn{2}{|c|}{1 Target } & \multicolumn{2}{|c|}{2 Targets } & \multicolumn{2}{|c|}{1 Target } & \multicolumn{2}{|c|}{2 Targets } \\
\hline & RT & $\mathrm{PE}$ & RT & PE & RT & PE & RT & PE \\
\hline \multicolumn{9}{|c|}{ Numeral Background, Matching (Numeral) Target } \\
\hline Regular & 1306 & 2.98 & 1241 & 3.87 & 1545 & 7.14 & 1755 & 6.25 \\
\hline Alternating & 1129 & 4.76 & 1484 & 6.55 & 1310 & 3.87 & 1697 & 2.38 \\
\hline Reverse & 1175 & 13.39 & 1612 & 5.95 & 1790 & 12.20 & 1907 & 5.95 \\
\hline Random & 1083 & 3.87 & 1488 & 11.61 & 1444 & 2.98 & 1707 & 5.36 \\
\hline \multicolumn{9}{|c|}{ Numeral Background, Mismatching (Letter) Target } \\
\hline Regular & 1024 & 0.60 & 1319 & 4.17 & 1378 & 5.95 & 1575 & 6.55 \\
\hline Alternating & 963 & 1.19 & 1224 & 5.06 & 1239 & 6.25 & 1714 & 7.14 \\
\hline Reverse & 1078 & 2.98 & 1452 & 5.36 & 1455 & 7.44 & 1732 & 6.25 \\
\hline Random & 861 & 0.60 & 1266 & 6.25 & 1153 & 1.79 & 1602 & 2.08 \\
\hline \multicolumn{9}{|c|}{ Letter Background, Matching (Letter) Target } \\
\hline Regular & 1302 & 4.46 & 1656 & 5.36 & 1597 & 6.55 & 1981 & 12.80 \\
\hline Alternating & 1240 & 4.46 & 1495 & 5.65 & 1412 & 5.95 & 1852 & 10.71 \\
\hline Reverse & 1320 & 3.57 & 1702 & 7.14 & 1392 & 8.33 & 2067 & 6.25 \\
\hline Random & 1248 & 5.36 & 1673 & 12.20 & 1406 & 6.25 & 2199 & 9.82 \\
\hline \multicolumn{9}{|c|}{ Letter Background, Mismatching (Numeral) Target } \\
\hline Regular & 1111 & 3.87 & 1275 & 5.65 & 1319 & 8.63 & 1561 & 1.49 \\
\hline Alternating & 1067 & 2.08 & 1208 & 2.68 & 1212 & 4.46 & 1503 & 6.25 \\
\hline Reverse & 1114 & 1.19 & 1391 & 8.93 & 1155 & 4.46 & 1658 & 6.84 \\
\hline Random & 977 & 2.98 & 1255 & 1.49 & 1306 & 5.06 & 1673 & 6.84 \\
\hline
\end{tabular}


absence $(\mathrm{p}<.01)$. Numeral targets also had a larger RT advantage with two targets $(132 \mathrm{msec})$ than with one $(2 \mathrm{msec})(\mathrm{p}<.001)$. On errors, too, the superiority of numeral targets was more evident with two targets $(\mathrm{p}<.05)$.

Category effect. With both letter and digit backgrounds, a mismatching target decreased both RT and errors $(\mathrm{p}<.05$ or better in all cases). In a combined analysis, the time savings were slightly, but not quite significantly, greater with two targets $(257 \mathrm{msec})$ than with one $(206 \mathrm{msec})(\mathrm{p}<.10)$. On trials having the conditions most often used in studying the category effect (search for presence, one target, one-row display), betweencategory trials were $93 \mathrm{msec}$ faster than within-category trials $(\mathrm{p}<.001)$.

\section{Discussion}

On numerals, why did regular order not help performance? Target class (letter, numeral) did not affect the basic findings, so the use of mismatching (letter) targets cannot explain the results. Deleting two numerals for possible target insertion may have weakened, but ought not to have eliminated, the familiarity effect. Two principles are suggested by the findings: (1) ascending order is better than descending order (Marcel \& Forrin, 1974; Parkman, 1971); (2) it helps to group numerals by odd versus even (Shepard, Kilpatric, \& Cunningham, 1975). Only the reverse order, which fared worst, fully violated both principles.

On letters, the superiority of the alternating order is puzzling. Its NUST sequence may have been particularly easy to process, but then the PURST sequence in the regular order also should have helped. Alternating order excelled even when the target and background class differed, so, just as with numerals, what mattered was not how the target fit into the context, but the context itself.

The fact that numerals helped more with a larger target set indicates that their aid was at memory comparison (Sternberg, 1969). Background order, in contrast, affected another stage, presumably encoding, since its effect on RT did not vary in any consistent fashion with target set size, just as is true for the word-superiority effect (Krueger, 1975). The category effect increased only slightly with two targets, so it, too, is located mainly at encoding (Krueger, 1984).

\section{EXPERIMENT 2}

The results of Experiment 1 suggested that odd and even numerals are encoded distinctively differently. Experiment 2 tested for this, as well as for a distinction between early (A to J) and late ( $Q$ to $Z$ ) letters. Other subsets of numbers and letters, for example, vowels and consonants (Staller \& Lappin, 1979), also may be highly distinctive.

Experiment 2 also tested for the effect of background order, using regular, reverse, and random orders (see Table 1), but did not adjust the letter sequences to equalize bigram frequency. An examination afterwards of the results indicated that letter, bigram, and trigram frequency could not explain the effects of background class and order on letter displays (Mayzner \& Tresselt, 1965; Mayzner, Tresselt, \& Wolin, 1965).

\section{Method}

There were 36 subjects. The method was the same as in Experiment 1, except for the following changes. A single target character was shown for $2 \mathrm{sec}$ before each block of trials. Search for presence was the only task used. To obtain a more sensitive test, all displays contained five rows, which were spaced $1.09 \mathrm{~cm}$ apart, so each display was $6.53 \mathrm{~cm}$ $\left(5.36^{\circ}\right)$ high.
On between-category blocks, the target was paired randomly with a member of the opposite set on early versus late letters. On digits, in order not to disrupt the regular or reverse numerical progression, each even numeral was paired with the next higher odd numeral (so the random-order odd set of 91537 became 02648 for the even set) for half of the subjects, and with the next lower numeral for the other half.

The target was present in half of the 10 regular trials in each block, appearing once at each of the five rows and once at five of the six withinrow positions. Eight target-background combinations (odd-odd, evenodd, odd-even, even-even, early-early, late-early, early-late, late-late) were crossed with three background orders, for a total of 24 regular blocks. There were six different random orderings of blocks and trials within blocks.

\section{Results}

Category effects. On numerals, target and background class (odd, even) did not interact on either RT or errors (F $\leq 1.58$ in both cases) (see Table 3). In fact, RT and errors were slightly higher, not lower, on betweencategory trials. On letters, there was a between-category advantage; target and background class (early, late) interacted on RT $(p<.001)$, especially with regular order $(\mathrm{p}<.01)$, but not errors $(\mathrm{F}<1)$ (see Table 3$)$.

Numeral background. Mean RT was lower when the target was an odd (vs. even) numeral ( $p<.025$ ), as were errors also $(p<.025)$. When the background contained odd (vs. even) numerals, however, errors were higher $(\mathrm{p}<.05)$.

Performance was somewhat worse on reverse order, but not significantly so on either RT or errors $(F \leq 1.24$ in both cases). On RT, background order interacted with background class (odd, even) $(p<.001)$. In separate analyses, order had an effect on RT with even backgrounds ( $p<.025)$, but not with odd ones $(p<.10)$. On even backgrounds, RT was lowest on regular order and highest on reverse order, especially if the target was odd (mismatching $)(\mathrm{p}<.05)$. In separate pairwise comparisons,

Table 3

Experiment 2: Mean Response Time (RT; in Milliseconds) and Percent Error Rate (PE) by Background Class, Target Type, and Background Order

\begin{tabular}{lllll}
\hline & \multicolumn{4}{c}{ Target Type } \\
\cline { 2 - 5 } $\begin{array}{l}\text { Background } \\
\text { Order }\end{array}$ & \multicolumn{2}{c}{ Matching } & Mismatching \\
\cline { 2 - 5 } \cline { 2 - 5 } & RT & Pdd Numeral Background & & PE \\
\hline Regular & 1788 & 4.17 & 1988 & 8.33 \\
Reverse & 1833 & 5.56 & 1784 & 6.67 \\
Random & 1473 & 3.33 & 1915 & 6.67 \\
& Even Numeral Background & & \\
Regular & 1830 & 5.00 & 1521 & 2.50 \\
Reverse & 1823 & 3.89 & 1970 & 5.83 \\
Random & 1772 & 5.28 & 1833 & 3.89 \\
& Early Letter Background & & \\
Regular & 2156 & 3.61 & 1770 & 4.72 \\
Reverse & 2211 & 6.67 & 2228 & 7.22 \\
Random & 2209 & 6.11 & 1941 & 5.00 \\
& Late Letter Background & & \\
Regular & 2290 & 5.28 & 1945 & 3.61 \\
Reverse & 2293 & 5.83 & 2080 & 4.72 \\
Random & 2083 & 3.89 & 2042 & 3.06 \\
\hline
\end{tabular}


RT was lower on regular order than either reverse or random order ( $p<.05$ or better in both cases).

Letter background. Background order affected RT $(p<.001)$ and errors $(p<.001)$, both of which were highest on reverse order and slightly lower on regular than random order. In separate pairwise comparisons, the reverse order was slower and less accurate $(p<.05$ or better in all cases) than either regular or random order.

Numeral vs. letter background. Numeral displays were lower on RT ( $p<.001)$, presumably because they involved sets of 5 rather than 10 characters.

\section{Discussion}

The lack of an odd versus even category effect is puzzling, because 21 subjects said afterwards that they had noticed the separate odd and even numeral displays, but only 13 said they had noticed the separate early and late letter displays. Furthermore, similarity rating of the numbers 0 to 9 as abstract concepts produces a consistent division into odd and even numbers (Shepard et al., 1975). Featural similarities between odd and even numerals may explain the results (Levine, 1977). Some subjects said that the odd-even contrast generally helped, but that 6 and 9 were quite similar and that it was very difficult to search for a 3 in a field containing $8 \mathrm{~s}$ or for an 8 in a field containing $3 \mathrm{~s}$.

Why did regular order help with even, but not odd, numerals? Perhaps the step size of 2 was more obvious in the even sequence, 02468, than in the odd sequence, 13579. Also, the numeral 0 in the even sequence may provide a better bridge between cycles, since it can represent either the next value above 9 or the next one below 1 (Parkman, 1971).

With letters in Experiment 2, as with numerals in Experiment 1, regular order did not help performance, whereas reverse order hurt. To the extent that reverse order possesses some familiarity in its own right, it ought to have helped performance (Marcel \& Forrin, 1974). Perhaps it hurt performance because it tended to trigger a less familiar (and thereby less efficient) right-to-left scan (Krueger, 1971), just as presenting letters in a mirror-reversed orientation seems to do (Krueger, 1976). The subjects did no better on early-letter than on late-letter displays, presumably because the displays allowed direct entry into the two regions of the alphabet (Hovancik, 1975; Klahr, Chase, \& Lovelace, 1983; Lovelace, Powell, \& Brooks, 1973).

\section{REFERENCES}

HovaNCIK, J. R. (1975). Reaction times for naming the first next and second next letters of the alphabet. American Journal of Psychology, 88, 643-647.

INGLING, N. W. (1972). Categorization: A mechanism for rapid information processing. Journal of Experimental Psychology, 94, 239-243.

JoNides, J., \& Gleitman, H. (1972). A conceptual category effect in visual search: $\mathrm{O}$ as letter or as digit. Perception \& Psychophysics, $12,457-460$.

Klahr, D., Chase, W. G., \& Lovelace, E. A. (1983). Structure and process in alphabetic retrieval. Journal of Experimental Psychology: Learning, Memory, and Cognition, 9, 462-477.

KRUEGER, L. E. (1971). Effect of direction of sequential presentation and redundancy on short-term recognition memory. Perception \& Psychophysics, 9, 121-124.

KRUEGER, L. E. (1975). Familiarity effects in visual information processing. Psychological Bulletin, 82, 949-974.

KRUEGER, L. E. (1976). Evidence for directional scanning with the orderof-report factor excluded. Canadian Journal of Psychology, 30, 9-14.

KRUEGER, L. E. (1984). The category effect in visual search depends on physical rather than conceptual differences. Perception \& Psychophysics, 35, 558-564.

KRUEGER, L. E., \& SHAPIRo, R. G. (1980). Why search for target absence is so slow (and careful!): The more targets there are, the more likely you are to miss one. Journal of Experimental Psychology: Human Perception and Performance, 6, 662-685.

LefTon, L. A., \& FisheR, D. F. (1976). Information extraction during visual search: A developmental progression. Journal of Experimental Child Psychology, 22, 346-361.

LEviNe, D. M. (1977). Multivariate analysis of the visual information processing of numbers. Journal of Multivariate Behavioral Research, 12, 347-355.

Lovelace, E. A., Powell, C. M., \& Brooks, R. J. (1973). Alphabetic position effects in covert and overt alphabetic recitation times. Journal of Experimental Psychology, 99, 405-408.

MARCEL, T., \& ForRIN, B. (1974). Naming latency and the repetition of stimulus categories. Journal of Experimental Psychology, 103, 450-460.

MAYZner, M. S., \& Tresselt, M. E. (1965). Tables of single-letter and digram frequency counts for various word-length and letter-position combinations. Psychonomic Monograph Supplements, 1 (No. 2), 13-32.

Mayzner, M. S., Tresselt, M. E., \& Wolin, B. R. (1965). Tables of trigram frequency counts for various word-length and letter-position combinations. Psychonomic Monograph Supplements, 1 (No. 3), 33-78.

McCARThy, S. V. (1976). Visual serial search across number and letter sets. Perceptual and Motor Skills, 43, 311-314.

McCarthy, S. V. (1979). College women with differential linguisticquantitative ability patterns: Performance on two visual serial-search tasks. Perceptual and Motor Skills, 49, 791-794.

NeIsser, U. (1967). Cognitive psychology. New York: AppletonCentury-Crofts.

Parkman, J. M. (1971). Temporal aspects of digit and letter inequality judgments. Journal of Experimental Psychology, 91, 191-205.

Shepard, R. N., Kilpatric, D. W., \& Cunningham, J. P. (1975). The internal representation of numbers. Cognitive Psychology, 7, 82-138.

Staller, J. D., \& LAPPIN, J. S. (1979). Word and nonword superiority effects in a letter detection task. Perception \& Psychophysics, 25, 47-54.

STERNBERG, S. (1969). The discovery of processing stages: Extensions of Donders' method. In W. G. Koster (Ed. and Trans.), Attention and performance II (pp. 276-315). Amsterdam: North-Holland. (Reprinted from Acta Psychologica, 1969, 30, 276-315) 